\title{
A History of Nuclear Medicine in the UK Radionuclide Investigation of the Brain
}

\author{
Peter J. Ell
}

The composite figure below, best describes the development of radionuclide labelled probes at the Institute of Nuclear Medicine, and its commitment to investigating the brain, in health and disease. From the very early days of blood brain barrier imaging with labelled pertechnetate, and the use of 3 " and 5" sodium iodide crystal scanners in the 60s, with added simple data processing in the 70s, progress was continuous, with the introduction of SPET, lyphophilic Tc99m labelled tracers for blood flow studies, investigating benzodiazepine receptor distribution in the female brain, the emergence of dopamine transporter imaging in patients with presumed Parkinson's disease, followed by PETCT and assessment of glucose metabolism with labelled FDG, and finally the UK introduction of PETMR and the investigation of the dementias, with labelled amyloid already in 2012 (Fig. 7.1).

Fig. 7.1 Evolving

Probes for

Radionuclide

Brain Imaging

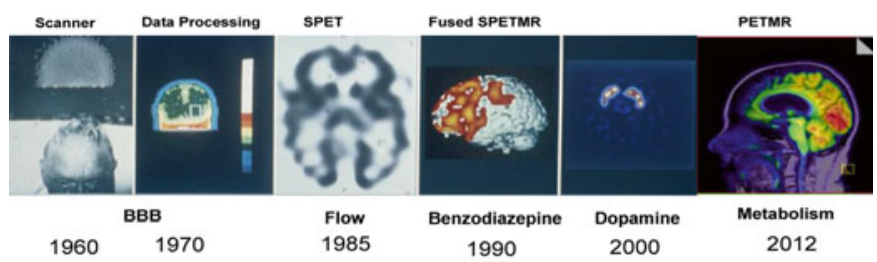

P.J. Ell

Department of Nuclear Medicine, Institute of Nuclear Medicine, University College London Hospitals,

UCLH NHS Foundation Trust, 235 Euston Road, London NW1 2BU, UK 
In 1985, scientists working at Amersham, UK, developed a first agent (hexamethylpropylenamine oxime -HMPAO - Ceretec) capable of traversing the intact blood brain barrier, with cerebral distribution according to blood flow $(\mathrm{CBF})$. Capable of being labelled with Tc-99m, this discovery represented a major step in the development of imaging agents for single photon emission tomography. A first in man study was performed at the Institute of Nuclear Medicine and reported at a meeting of the British Institute of Radiology in February 1985.

This development, for which Amersham twice received Queen Industry Awards, led to a significant clinical program at the Institute. First patterns of regional cerebral blood flow were published (Lancet 1985), cerebral damage in HIV infection was studied (Lancet 1987), the patterns of CBF in dementia investigated (J Cerebral Blood Flow and Metabolism 1988 and J. of Neurology, Neurosurgery and Psychiatry, 1989). Patients with focal epilepsy were investigated (Lancet 1989 and Neurology 1992), stroke (Lancet 1989), follow up studies in dementia published (JNM 1989 and J. Neurology, Neurosurgery and Psychiatry 1991, Brit. Med. J. 1992), in traumatic intracerebral haematoma (J. of Neurology, Neurosurgery and Psychiatry 1991). A start in neuroactivation imaging was made (European J Nuclear Medicine 1991 and J. of Neural Transmission 1992), and the effect of depression on CBF investigated (J. of Affective disorders 1993).

This development led to one of the most productive research periods of the Institute, with a long list of peer reviewed publications. A clinical service was initiated, world wide HMPAO SPET is still the most common nuclear medicine imaging procedure for CBF studies.

The advent of PET would of course play a big role, even with the simple use of labelled glucose, a metabolic marker acting as a surrogate marker for brain blood flow, in most circumstances where the brain blood barrier is not impaired (such as epilepsy, and the dementias, for example). This has now led to a routine clinical activity in the investigation of non lesional patients with focal epilepsy (namely patients with normal or equivocal MR studies ), where with FDG PETCT it is possible in one third of all referrals (in this difficult population) to offer clinical information with management utility.

\subsection{Neuroreceptor Studies}

With single photon emission tomography being at the time the only practical tomographic imaging technology for radiolabeled probes, Costa and staff at the Institute published very early on an important study, characterizing in vivo an I-123 labelled neuroreceptor for the D2/D3 dopaminergic system (European J Nuclear Medicine 1990) - 3-iodo-6-methoxybenzamide -IBZM. We show an IBZM study in a normal and a medicated patient, over a period of time, and the different degrees of receptor blockade in the striatum (Fig. 7.2). 


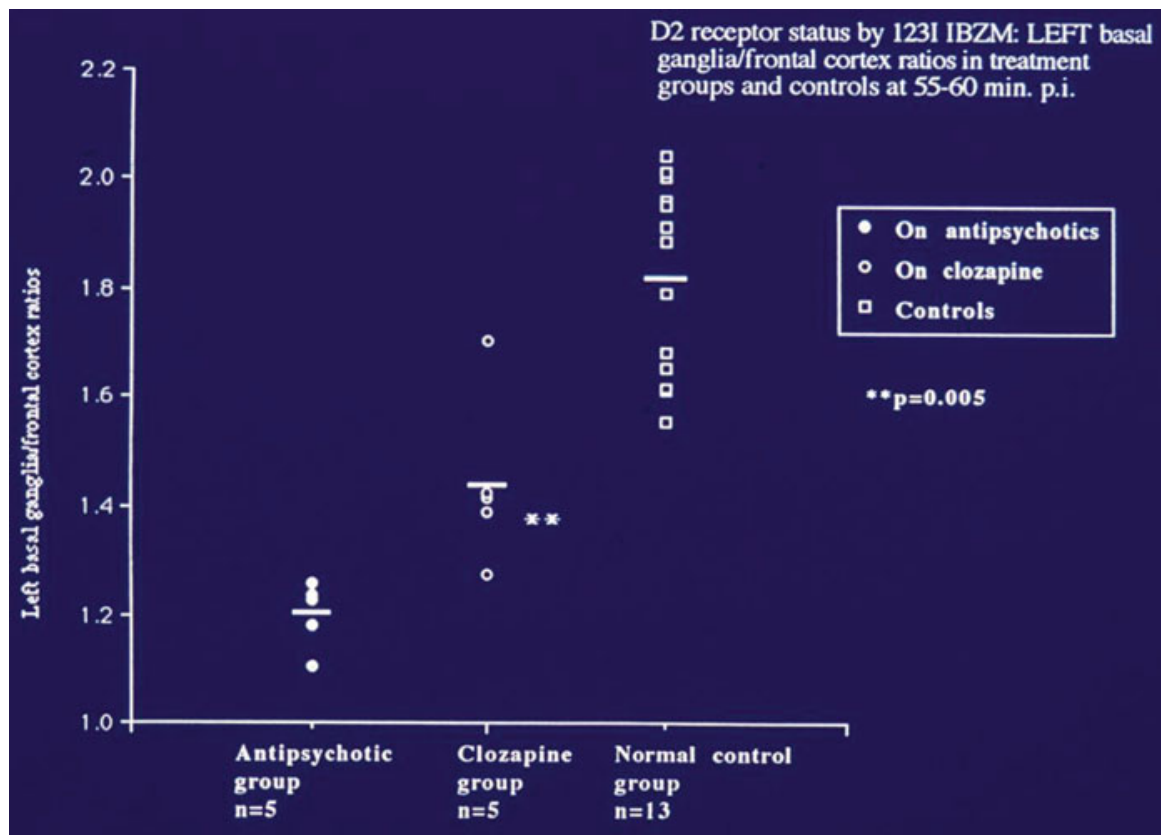

Fig. 7.2 Investigating the Clozapine Hypothesis

This was important work, and attracted to the Institute a young psychiatrist, from the Institute of Psychiatry at Denmark Hill (the late Lyn Pilowsky). Lyn was an enthusiastic researcher and soon obtained a Fellowship from the Medical Research Council (MRC).

Lyn was especially interested in managing patients with schizophrenia. There was indisputable pharmacological evidence for dopaminergic dysfunction in schizophrenia. Dopamine receptor blockade was shown to be an invariate requirement for the activity of antipsychotic drugs. The administration of clinical doses of antipsychotic medication resulted in a substantial degree of striatal D2 dopamine receptor occupancy in humans. Lyn wished to test the hypothesis that the D2 imaging ligand IBZM would be able to identify differences in D2 receptor activity in a population of schizophrenic patients (untreated drug naïve patients compared to controls, antipsychotic treated responders compared with non responders, and treated schizophrenic patients with tardive dyskinesia, compared with those without.

A seminal publication in The Lancet presented her findings : clozapine, single photon emission tomography, and the D2 dopamine blockade hypothesis of schizophrenia (Lancet 340, 199-202, 1992 ). The study showed beyond doubt that patients on typical antipsychotics showed poor response, despite D2 receptor blockade. 
Significant clinical improvement occurred in all patients on clozapine, but at a lower level of D2 blockade by the drug. These findings suggested a more complex relation (rather than the hitherto suspected linear relation) between D2 blockade and clinical efficacy! In an important review in The Lancet, reviewing the 10 most important publications of that decade in psychiatry, Lyn's contribution was clearly acknowledged (Flaum and Andreasen 1997)

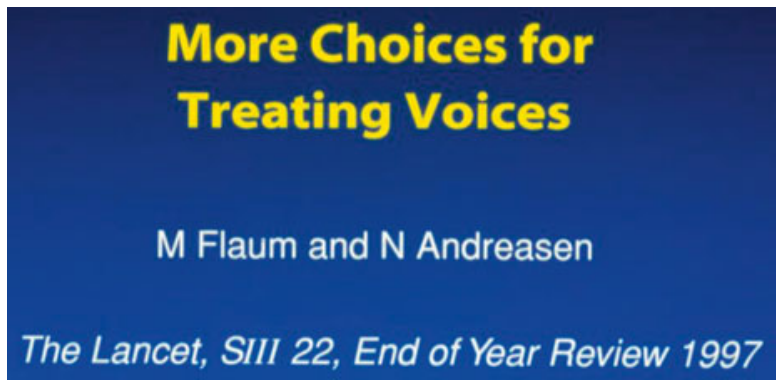

Between 1985 and 1990, some 40+ peer reviewed publications emanated from the Institute in respect to brain imaging. Whilst HMPAO became the most widely imaging probe used for blood flow SPET studies of the brain, other probes and approaches were investigated.

A further area of interest developed, with major input from the cardiac surgeons and psychologists. It was known for some time that patients undergoing coronary bypass surgery, often presented with a degree of cognitive impairment. If you were an excellent chess player pre-operatively, you may not be performing as well in the post operative period. To investigate organ function prior interventions, had met with recent success. One of our studies showed the clinical relevance of assessment cardiac ejection fraction prior aortic surgery. It was clearly possible to stratify patients into different risk categories (Mosley et al Brit J Surgery 1985, Ell The Lancet 1986).

And so it was decided to investigate brain blood flow, during and after 8 days and 8 weeks post coronary bypass surgery. Labelled xenon-133 was used for this purpose. A series of publications assessed the effect of surgery on this patients, the time required for their recovery and the modifications needed during surgery to minimise this risk (Smith et al., the Lancet 1986, Venn et al. The Brit Heart J 1987 and 1988, Treasure et al., Europ J CardioTh Surgery 1989).

Early studies with labelled HMPAO in patients with refractory and focal epilepsy showed the potential of interictal and ictal imaging. Again a number of publications emerged and a limited clinical service developed. In recent times a service has developed based on FDG PETCT and the investigation of MR non lesional patients with refractory and focal epilepsy. We show below a typical example where FDGPET aids in the localization of the epileptic focus (Fig. 7.3). 


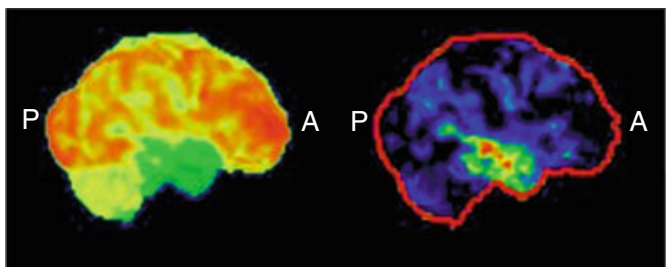

Right medial

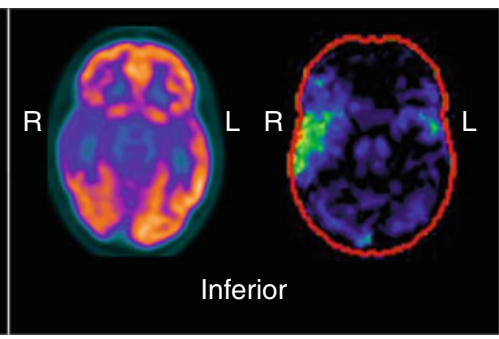

Fig. 7.3 Refractory epilepsy. Scalp video EEG telemetry suggests that focus arises from right frontal or temporal lobes. MRI is unremarkable. For intracranial EEG planning. There is focal right temporal lobe hypometabolism. Localization to right temporal lobe

Open Access This chapter is distributed under the terms of the Creative Commons AttributionNoncommercial 2.5 License (http://creativecommons.org/licenses/by-nc/2.5/) which permits any noncommercial use, distribution, and reproduction in any medium, provided the original author(s) and source are credited.

The images or other third party material in this chapter are included in the work's Creative Commons license, unless indicated otherwise in the credit line; if such material is not included in the work's Creative Commons license and the respective action is not permitted by statutory regulation, users will need to obtain permission from the license holder to duplicate, adapt or reproduce the material.

\section{Key References}

Bressan RA, Erlandsson K, Jones HM, Mulligan R, Flanagan RJ, Ell PJ, Pilowsky LS. Is regionally selective D2/D3 dopamine occupancy sufficient for atypical antipsychotic effect? An in vivo quantitative [123I] epidepride SPET study of amisulpride-treated patients. Am J Psychiatr. 2003;160:1413-20.

Burns A, Philpot M, Costa DC, Ell PJ, Levy R. The investigation of Alzheimer's disease with single photon emission tomography. J Neurol Neurosurg Psychiatry. 1989;52:248-53.

Ell PJ, Jarritt PH, Deacon J, Brown NJG, Williams ES. Emission computerised tomography. A new diagnostic imaging technique. Lancet. 1978;II:608-10.

Ell PJ, Harrison M, Lui D. Cerebral blood flow with ${ }^{123}$ Iodine labelled amines. Lancet. 1983;1:1348-52.

Ell PJ, Cullum I, Costa DC. Regional CBF mapping with a new Tc-99m labelled compound. Lancet. 1985;II:50-1.

Pilowsky LS, Costa DC, Ell PJ, Murray RM, Verhoeff NPLG, Kerwin RW. Clozapine, single photon emission tomography, and the D2 dopamine receptor blockade hypothesis in schizophrenia. Lancet. 1992;340:199-202.

Smith PLC, Newman SP, Ell PJ, Treasure T, Joseph P, Schneidau A, Harrison MJG. Cerebral consequences of cardiopulmonary bypass. Lancet. 1986;I:823-5. 


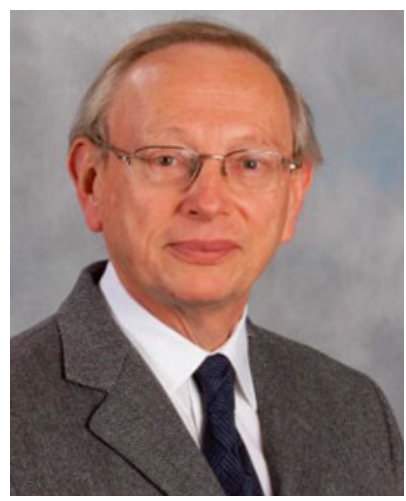

Peter J. Ell After graduation from Lisbon University in 1969, I became a junior staff member in a biology laboratory attached to a nuclear research reactor just outside Lisbon. My first assignment was to write a report for the Government, on the use of radiation as a method to sterilize once only use products, such as disposable syringes, then a true novelty. So I visited an establishment in Reading, produced my report, which led to a grant to attend the 2nd London University MSc degree course in nuclear medicine, in 1971. Many of us taped all the lectures, and we learned more about physics than nuclear medicine, and almost nothing about radiochemistry! I recall a comment from a colleague from Toronto, who, after hearing so many lectures on beta particles, enquired whether gamma rays where less relevant to nuclear medicine. After a 2 year stint as a Registrar at the INM and the Middlesex Hospital, I accepted a Lancet advertised post, to lead a new NM department in Feldkirch, Austria, in 1974. There I caused some local stir, for introducing radioimmunoassay's, in competition with a local conventional biochemistry lab, but obtained clear support from Vienna and the local Government.

1976 saw my appointment as Senior Lecturer at the Middlesex Hospital Medical School, not without trepidation and requesting a time off/cooling period, before acceptance (unheard off at the time). The CT scanner arrived at The Middlesex by end 1976 - by 1978 , we published our first paper on single photon emission tomography. Cross sectional imaging and turf battles had truly arrived and changed our field. Progress and transformation was rapid, and it was fun! SPET became routine for most of our studies (brain, heart, lung, liver). Nuclear Medicine emerged as a separate medical speciality, recognized by the UEMS and Europe, through valiant effort from physicians working in Europe.

My appointment to the established UCL chair in Nuclear Medicine occurred in October 1987 we had a great team of clinicians, physicists, pharmacists, nursing and technical staff, and plenty of post-graduates - again work was fun, fun breathes success, and success brings more fun. International commitments began to take place.

As first elected Secretary of the European Association of Nuclear Medicine (1987-1993), I was able to guide the development of this Society. With the European Industry Association for Nuclear Medicine, we discussed the future direction and regulatory practices of this medical speciality in Europe.

As the Editor in Chief of the European Journal of Nuclear Medicine (1990-2003), I was able to promote the science and medicine of nuclear medicine. The Impact Factor grew each year, beating the competition by the end of my term.

As the elected President of the European Association of Nuclear Medicine (1994-1996), I was responsible for the overall policy of the Association and its relationship with EC, UEMS, WHO, IAEA and WFNMB.

By January 2002, we introduced PETCT to the first UK patient - multimodality imaging was truly born. At my UCL retirement in 2009, and 38 years after arriving in London, PETMR was introduced to the INM and the UK.

Peter J. Ell FMedSci DR HC A $\Omega$ A FRCP FRCR

Professor Emeritus UCL

Trustee University College London Hospitals Charity 